\title{
LOCKE Y CONDILLAC EN TORNO AL LENGUAJE
}

\author{
Ismael MARTÍNEZ LIÉBANA \\ Universidad Complutense. Madrid
}

En este artículo nos ocuparemos del análisis que Condillac lleva a cabo de la vida mental superior. Nuestro propósito es en concreto examinar y valorar en sus justos términos la concepción condillaciana concerniente a la génesis y desarrollo de las ideas complejas del espíritu y de la reflexión consciente, y ello en estrecha relación con la teoría del lenguaje que mantiene el autor.

En este sentido, en primer lugar, aludimos a lo que Condillac considera incoherencias del planteamiento de Locke, quien, a pesar de su inicial declaración expresa de empirismo, recurre en el sistema a principios no justificables desde una posición empirista radical. La crítica de Condillac a esta inconsistencia lockiana es contundente, la cual, empero, va a plantearle a su vez la difícil problemática de dar cuenta, habiendo negado el poder de síntesis presente en Locke, de la aparición de las operaciones intelectuales superiores. La respuesta que Condillac aporta a tal problema será el lenguaje, entendido como sistema de signos convencionales. A este respecto veremos que la concepción condillaciana del lenguaje será muy diferente de la de su maestro; mientras que para éste el sistema de signos presenta ante todo una función comunicativa, para Condillac es, ante todo, el medio indispensable de fijación de ideas y, por ende, el factor posibilitador de la reflexión y de la vida mental superior. El lenguaje, por tanto, cuyo origen preténdese radicar en las facultades elementales del cognoscente (principalmente en la atención y en la imaginación), va a dar paso a la reflexión y a las operaciones de ella derivadas.

La intención última que perseguimos en las páginas que siguen es mostrar cómo Condillac entiende que con la apelación al lenguaje convencional, cuyo origen pretende situar en última instancia en la sensación misma, se resuelve el 
problema de la heterogeneidad y discontinuidad entre lo inferior y lo superior del espíritu, entre lo simple y lo complejo de la conciencia. Por medio de él, el desarrollo de la vida psíquica intelectual se produce de manera continua, progresiva y sin saltos. Por él, la posibilidad de reducir todos los conocimientos y operaciones del psiquismo al principio único de la sensación, se convierte, según Condillac, en hecho manifiesto e incontrovertible.

\section{Las incoherencias del sistema lockiano}

Condillac, animado por el ideal newtoniano que impone la reducción de fenómenos en apariencia heterogéneos a un principio único, pretende en su investigación dar explicación del entero edificio del conocimiento humano apelando a la sola sensación. A partir de ésta, y por un desenvolvimiento riguroso y progresivo, habrá de ser posible dar cuenta de las múltiples y sucesivamente más complejas formaciones de lo anímico. No es lícito, pues, hacer uso en esta empresa de principios ajenos al meramente sensible; el puro dato sensorial habrá de bastar para entender la génesis y desarrollo incluso de las operaciones más elevadas del entendimiento.

De ahí que Condillac no pueda seguir en esto a su maestro. No puede en efecto permanecer por más tiempo fiel a sus principios. Condillac quiere ser empirista en sentido estricto, pretende llevar el empirismo a sus últimas consecuencias, y para ello, no puede admitir ciertas incoherencias presentes en el sistema de Locke. Este había declarado que ninguna idea innata existía, que todo conocimiento redúcese en última instancia a la experiencia sensible; más ciertas dificultades en la teoría de la percepción y en la explicación de las ideas complejas habíanle hecho dudar (si no de forma expresa, sí al menos implícitamente) de su primitiva profesión de fe empirista. Veamos en detalle tales incoherencias.

\section{A) Los juicios inconscientes}

Al afrontar la teoría de la percepción, Locke matiza ya su tesis inicial del empirismo radical. Habíase en efecto negado a no ver en la sensación sino un estado meramente pasivo y receptivo, en que el alma es comparable a la cera que recibe la impronta de un sello. Renunciando de este modo a la primitiva posición empirista y sensista, había reconocido en toda percepción la existencia de 
una secreta actividad del espíritu, por la que juicios a menudo inconscientes vienen a unirse a las impresiones experimentadas.

Cuando situamos delante de nuestros ojos un globo esférico... - había escrito-, es seguro que la idea que se imprime en nuestra mente al contemplar ese globo es la de un círculo plano con varias sombras y con diversos matices de luz y de tonos que hieren nuestros ojos. Pero como ya estamos habituados por la costumbre a percibir el aspecto producido por los cuerpos convexos en nosotros y los cambios que experimentan los reflejos luminosos según las diferencias de las formas sensibles de los cuerpos, el juicio, a causa de una costumbre reiterada, cambia de manera inmediata las apariencias en sus causas, de forma tal, que lo que realmente es una variedad de sombra o de color reunida en la forma, la hace pasar por un cambio de la forma y se forja para él mismo la percepción de una forma convexa y de un color uniforme, cuando la idea que percibimos no es sino la de un plano coloreado de forma diversa, según se puede ver en los cuadros ${ }^{1}$.

El juicio, pues, se vincula estrechamente a la percepción; ésta no se da en estado puro; aparte de ella, la mente, por si sola, aporta un nuevo elemento que viene a unirse a ésta. Es lo que de forma clara y explícita muestra el problema planteado a Locke por Molyneux; éste había supuesto a un ciego de nacimiento, conocedor por el tacto de las diferencias existentes entre un cubo y una esfera; había imaginado también una operación quirúrgica capaz de concederle repentinamente la vista. El problema concreto planteado era saber si la vista, por sí sola y sin ayuda del tacto, sería capaz ahora de hacer distinguir al recién vidente el cubo y la esfera en cuestión. La respuesta de Locke y de Molyneux había sido claramente negativa, "... porque aunque el hombre en cuestión tenga la experiencia del modo en que afectan a su tacto una esfera y un cubo, no tiene sin embargo la experiencia de que aquello que afecta a su tacto de tal o cual forma podrá hacerlo de esta o aquella manera a su vista, ni de que un ángulo saliente del cubo, que causaba una presión desigual en su mano, se muestre a su vista en forma de cubo»2.

Locke había entendido así que la percepción no es simple y que a toda sensación el entendimiento añade una nueva impresión o un recuerdo, que incor-

1 J. LOCKE, An Essay Concerning Human Understanding, II, 9, \$8, in John LOCKE, An Essay Concerning Human Understanding, edited with an introduction, critical apparatus and glossary by Peter H. Nidditch, Oxford at the Clarendon Press, 1975, p. 145.

2 J. LOCKE, ibidem. 
pora al dato bruto primitivamente captado. El espíritu empirista que debía animar la obra de Locke quedaba así claramente afectado. Para explicar el oscuro trabajo del pensamiento, que interpreta la sensación, había admitido la existencia de una actividad propia e irreductible del entendimiento. Había invocado la existencia de una potencia que no podía reducirse por entero a los datos sensoriales originarios. En el sistema se introducía así, de forma solapada pero absoluta, un principio misterioso y nuevo.

\section{B) La facultad de sintesis}

El ideal empirista que había animado a Locke al concebir el Essay se ve, pues, seriamente afectado cuando admite en la percepción juicios inconscientes cuyo origen se revela supra-empírico. No es la sensación de donde dimanan tales elementos judicativos. Estos se añaden a ella desde fuera matizándola y completándola.

No obstante, si grave es esta inconsecuencia para la unidad del sistema, mayor quebranto supone en ella la admisión en el sujeto cognoscente de un poder autónomo y superior de síntesis. En efecto, Locke había sostenido que el espíritu comienza por recibir ideas simples por las dos fuentes de conocimiento que posee: la sensación y la reflexión. Según él: «Las observaciones que hacemos sobre los objetos sensibles externos o sobre las operaciones internas de nuestra mente, las cuales percibimos y sobre las que reflexionamos nosotros mismos, es lo que provee a nuestro entendimiento de todos los materiales del pensar. Estas son las dos fuentes de conocimiento de donde parten todas las ideas que tenemos o que podamos tener de manera natural" ${ }^{3}$. Según Locke, esas ideas habían de ser consideradas como materiales básicos que el entendimiento tiene por función elaborar y desarrollar. La mente da origen, a partir de ellas y por su fuerza autónoma, al vasto mundo de las ideas compuestas, más ricas, completas y acabadas. Las ideas abstractas (objeto de la reflexión de los filósofos), por alejadas y supraempíricas que parezcan, no son en última instancia sino ideas simples de sensación y reflexión, reunidas y articuladas de cierta manera. No obstante, la función de síntesis que reúne las ideas simples formando ideas complejas, no deriva ella misma de tales ideas simples, datos inmediatos y materiales primordiales del conocimiento. Locke entiende que $!$ poder de combinar las ideas de sensación y reflexión há-

3 J. LocKE, Essay..., II, 1, \$2, p. 104. 
llase al margen de lo estrictamente empírico. Es lo que parece desprenderse ya de las primeras líneas del libro II del Essay: "Una vez que el entendimiento está provisto de esas ideas simples -escribe-, tiene la facultad de repetirlas y ensamblarlas con una variedad casi infinita, de tal forma que puede formar nuevas ideas complejas a su gusto" 4 . Y más adelante recalca esta idea acentuando el carácter activo y espontáneo del espíritu en la elaboración de las ideas complejas: "Aunque la mente sea puramente pasiva en la recepción de sus ideas simples - dice-, ejerce no obstante varios actos propios, por los cuales forma a partir de sus ideas simples que utiliza como materiales y fundamentos del resto, las demás" 5 . Una vez que se ha hecho con las ideas simples, el espíritu no se limita a una simple contemplación de los objetos externos aprehendidos por sensación o de las operaciones interiores captadas por reflexión; puede, en virtud de un poder autónomo e irreductible, combinar variadamente las ideas que ha adquirido pasivamente y elaborar con ellas ideas complejas que no había recibido nunca así agrupadas 6 .

Locke había reconocido así la existencia en el sujeto de una actividad espiritual independiente de los datos sensibles. Habíase visto forzado a admitir una función de síntesis capaz de explicar la formación de las nociones más abstractas y complejas de lo anímico. Mas con la apelación a semejante facultad combinatoria había renunciado a su proyecto original; había rehusado dar explicación del entendimiento todo por reducción al dato único y primordial de lo empírico. Lejos de mantenerse en la línea inicial de que todo en el hombre tiene su fuente en la experiencia, había apelado a un poder innato, misterioso e inexplicable sensiblemente.

Así pues, el proyecto que había dado origen al Essay podía parecer en principio nuevo y atractivo, más la ejecución del mismo no respondía en absoluto al plan trazado. Por falta de firmeza, pero más bien a causa de un sentido agudo de lo concreto que le había hecho olvidar la lógica del sistema para describir más fielmente lo real, Locke habíase contentado con explicaciones vagas y escasamente satisfactorias. A pesar de una intención decidida de reducir el entendimiento todo a los solos datos de los sentidos, no había podido definir claramente el origen de las facultades más elevadas del espíritu. Será precisamente la obra de Condillac la que habrá de corregir semejante deficiencia.

\footnotetext{
J. LOCKE, op. cit., II, 2, $\$ 2$, p. 119.

J. LocKE, op. cit., II, 12, $\$ 1$, p. 163.

6 Cfr. J. LoCKE, op. cit., II, 12, $\$ 2$, p. 164.
} 


\section{La crítica de Condillac}

El espíritu sistemático y riguroso de Condillac se ve profundamente resentido por las incoherencias del sistema lockiano. El no puede admitir en su pensamiento entidades confusas, no debidamente justificadas a partir de principios claros y bien determinados. Concibe la filosofía como un sistema de ideas riguroso, en que cada parte se relaciona claramente con el resto y en que todas derivan en última instancia de una primera y fundamental. "Un sistema -escribe- no es otra cosa que la disposición de las diferentes partes de un arte o de una ciencia en un orden en el que se apoyan todas mutuamente, $y$ en el que las últimas se explican por las primeras" 7 . De ahí que nada pueda aparecer en el sistema sin ocupar un lugar determinado, esto es, sin que pueda ser finalmente reducido al principio único o fundamento de éste.

Condillac no puede por tanto admitir las oscuridades e incertidumbres del pensamiento de Locke; no puede aceptar que se introduzcan en su filosofía presupuestos inexplicables y abstracciones infundadas; en definitiva, no puede tolerar, en aras de un rigor empirista estricto, los restos de innatismo todavía presentes en Locke.

\section{A) Negación de los juicios inconscientes}

La idea de Locke de que el espíritu añade a la percepción elementos intelectuales de forma inconsciente, es considerada por Condillac como absurda y contradictoria, y consagra a su refutación todo un capítulo del Essa ${ }^{8}$. No concibe que la sensación haya de requerir elementos extrasensibles para hacer captar al cognoscente lo que los sentidos directamente y por ellos mismos pueden aprehender. Su actitud ante la idea lockiana de los juicios inconscientes es totalmente escéptica; en primer lugar, y por principio, el sujeto carece de conciencia de tales juicios; por ello, nada le autoriza a pensar que efectivamente los forme. Por otra parte, si este fuera el caso, no los confundiría con la sensación; distinguiría por el contrario claramente lo que es objeto de percepción y lo que es actividad propia del entendimiento. Finalmente, el conocimiento de que las

7 Condillac, Traité des sistèmes, cap. I; t. I, p. 121a. Citamos a Condillac por la edición de sus obras filosóficas, preparada por Georges LE RoY: Oeuvres philosophiques de Condillac, texte établi et présenté par G. Le Roy, Presses Universitaires de France en 3 tomos: t. I (1947), t. II (1948), t. III (1951).

8 Cfr. Condillac, Essai..., I, VI; t. I, pp. 53a-59b. 
imágenes sensibles de los objetos son alteradas por los contenidos de índole judicativa, supone en el entendimiento nociones abstractas que sólo los expertos poseen. Así pues, los sentidos proporcionan directamente y sin mediación alguna todo lo que aportan. En el momento de la percepción, el espíritu no realiza ningún trabajo particular para añadir a lo que sensiblemente aparece elementos cognoscitivos extraídos del intelecto. Cada dato sensible se basta por sí mismo; nada intelectual es preciso para aportar al cognoscente información sobre la realidad sensible de los objetos.

Locke y Molyneux se han equivocado, pues, al pensar que el recién vidente no distinguiría por la vista y sin la ayuda del tacto el cubo y la esfera. Sin du$\mathrm{da}$, al abrirse sus ojos a la luz por vez primera no goza enseguida del espectáculo que produce el juego de luces y de sombras; sólo la reflexión puede descubrírselo. Mas, por nuestra parte, cuando observamos, por ejemplo, un cuadro complejo, ¿no debemos también realizar un cierto esfuerzo?, ¿no nos vemos obligados a considerar por separado unas tras otras todas sus partes? Nò es extraño, pues, que el recién vidente precise de un período de reflexión para distinguir las imágenes que percibe. Le hace falta tiempo, mas si analiza cuidadosamente lo que ve, discernirá finalmente por los solos datos visuales el cubo y la esfera. Los distinguirá, puesto que reconocerá en ellos las mismas ideas que había adquirido por las sensaciones táctiles?.

Condillac reconoce que su tesis se halla en contradicción con los resultados de ciertas experiencias llevadas a cabo con ciegos de nacimiento. En su obra recuerda especialmente el caso del joven ciego, a quien Cheselden en 1728, tras haberle operado de cataratas, le otorgó el sentido de la vista. Este joven, en un principio, no distinguió nada por la vista; era incapaz de discernir las formas, tamaños y distancias de los objetos que le presentaban; todos ellos le parecían tocar sus ojos, como los objetos del tacto tocaban su piel ${ }^{10}$. A pesar de estas dificultades, Condillac no renuncia a su explicación; el hecho de que el recién vidente necesite de tiempo para distinguir los objetos por el solo medio de la vista, no significa que no reconozca por ella las mismas ideas aprehendidas a través del tacto; únicamente, y puesto que sus ojos carecen de ejercicio, requiere de tiempo, precisa de una reeducación y de una adaptación, conseguibles por entero a través de los meros datos visuales ${ }^{11}$.

\footnotetext{
9 Cfr. CondillaC, op. cit., I, VI, $\$ 14 ;$ t. I, p. 57a-b.

10 Cfr. Condillac, loc. cit., $\$ 15$; t. I, pp. 57b-58a.

11 Cfr. Conoillac, loc. cit., 16; t. I, pp. 58b-59a.
} 
A su juicio, por tanto, Locke ha cometido un error al hacer intervenir en la percepción elementos extrasensibles de carácter judicativo e inconsciente; Berkeley, por su parte, agravará aún más este error, al sostener que incluso para el vidente nato la vista no proporciona por sí misma las nociones de figura, tamaño y distancia, sino que simplemente las sugiere por la conexión existente entre las sensaciones visuales y las táctiles. No obstante, como es sabido, Condillac se adhiere plenamente a esta tesis al conferir al tacto en el Traité des sensations el papel preponderante en la captación de los objetos externos.

\section{B) Negación de la facultad de síntesis}

Condillac no puede admitir tampoco la existencia en el espíritu de un poder autónomo de síntesis, independiente e irreductible al dato sensorial originario. No piensa, desde luego, que las ideas simples de sensación y reflexión se hallen aisladas e inconexas en el entendimiento. El es, por el contrario, uno de los que más ha insistido en la asociación de las ideas; a su juicio, la asociación hállase estrechamente relacionada con la atención; de ella depende y a ella se reduce en última instancia. La atención, a su vez, depende de las pasiones, del temperamento y, en definitiva, de las necesidades del cognoscente. La atención liga así las ideas en función del interés que éstas presentan para la acción. "A una necesidad -escribe Condillac- está ligada la idea de la cosa que es propia para satisfacerla; a esta idea, la de lugar en que se encuentra esta cosa; a ésta, la de las personas vistas en él; a ésta última, las ideas de los placeres $o$ de los pesares que se han recibido, y otras varias. Es posible observar incluso que, segun se extiende la cadena, se subdivide en diferentes eslabones; de manera que, cuanto más se aleja uno del primer eslabón, más se multiplican éstos. Una primera idea fundamental está ligada a otras dos o tres; cada una de éstas a un número igual o aún mayor, $y$ así sucesivamente» ${ }^{12}$. La relación que se establece entre todas las ideas del sujeto es tal, que podría considerarse a éstas como formando una única cadena, de la que partirían diferentes subdivisiones. Como dice Condillac: "Asi pues, de todos nuestros conocimientos no se formaría más que una sola y misma cadena, cuyos eslabones unirianse en ciertos anillos, para separarse en otros" ${ }^{13}$.

12 Condillac, Essai..., I, II, III, $\$ 29 ;$ t. 1, p. $17 \mathrm{~b}$.
13 Condillac, loc. cit., $\$ 30 ;$ t. I, p. $17 \mathrm{~b}$. 
Ahora bien, nada nuevo y original nace de estas asociaciones entre ideas. Condillac entiende que el pensamiento permanece a ese nivel puramente pasivo y receptivo. No depende de él unir entre sí las diferentes ideas; las asociaciones que se forman entre éstas son por completo accidentales y fortuitas; ninguna facultad de síntesis las determina. La asociación de ideas revélase, pues, enteramente impotente para dar lugar a la aparición de operaciones nuevas y superiores. Para efectuar una síntesis original de ideas simples, sería preciso que la asociación de éstas fuese producida voluntariamente por la sola inteligencia, cuando en realidad no es debida sino a un conjunto de condiciones exteriores puramente fortuitas. El espíritu no es dueño de usar a su guisa de esas asociaciones; más bien es el esclavo de ellas.

Así pues, Locke se ha equivocado de nuevo; el entendimiento no tiene el poder de comparar y de unir por sí mismo con una variedad casi infinita las ideas que ha recibido por sensación y reflexión. «El (Locke) —escribe Condillacsupone, por ejemplo, que una vez que el alma recibe ideas por los sentidos, puede a su gusto repetirlas, componerlas, unirlas juntas con una variedad infinita, y hacer toda suerte de nociones complejas» ${ }^{14}$. Mas esto revélase incierto, pues «... hemos experimentado sensaciones, mucho tiempo antes de saber extraer de ellas las ideas correspondientes»15. Hay, pues, un proceso por el que pasamos de la sensación a las diferentes operaciones del alma y que Locke no describe, contentándose con hacer intervenir los poderes de combinación, de relación y de abstracción, que caracterizan la actividad propia del entendimiento sobre las ideas simples salidas de la experiencia. Y la tarea que Condillac se fijará será precisamente la descripción de la génesis de las operaciones del alma, desde el grado más bajo de la percepción a las formaciones últimas del entendimiento.

F. Duchesnau, en su artículo "Condillac critique de Locke», escribe lo siguiente:

Condillac reprochaba a Locke haberse detenido a mitad de camino en la derivación empírica de los conocimientos, al contentarse con presuponer los poderes de abstracción, de combinación y de correlación de las ideas y con describirlos como simples modos del pensamiento, capaces de proporcionar las "ideas of reflexion". En el Essai sur l'origine des connaissances humaines, Condillac intenta descubrir la ley de génesis de los poderes del alma, en la

14 CondILLAC, op. cit., Introduction; t. I, p. 5 b.

15 Condillac, ibidem. 
medida en que se analizan los unos y los otros. Hemos intentado mostrar que el empirismo de Locke se acomoda a una estructura a priori de poderes de conocimiento. La percepción de la idea simple y la combinatoria de las ideas complejas implica para él la autonomía epistemológica del sujeto pensante ${ }^{16}$.

Así pues, la posición de Condillac es clara. Se niega a creer en la existencia de una facultad misteriosa del espíritu; estima que la sensación es simple y la asociación de ideas, totalmente maquinal. Suponer en el espíritu un poder oscuro, como ha hecho Locke, implica negar el principio mismo del empirismo $y$, por tanto, mantener todavía restos de innatismo en la explicación de la mente. Se hace, pues, necesario un replanteamiento del problema; una nueva vía debe ser emprendida, a fin de evitar las inconsecuencias e incertidumbres del pensamiento de Locke.

\section{El lenguaje como origen del desarrollo mental superior}

El carácter sistemático y la exigencia de rigor plantean, no obstante, a Condillac un grave problema. Para Locke, que había postulado en la mente un poder autónomo de síntesis capaz de combinar entre sí las ideas simples de sensación y reflexión, toda dificultad de dar cuenta de las ideas complejas y de las operaciones superiores del entendimiento, había desaparecido. Puesto que, según él, la mente posee un poder combinatorio, la explicación del origen de la reflexión y de las formaciones cognoscitivas más elevadas era bien sencilla; en definitiva, el problema había quedado resuelto eliminándolo.

Condillac, por su parte, no puede seguir esta vía. Habiendo reprochado a su maestro la pervivencia en el sistema de elementos innatistas incompatibles con el principio empirista, ha de renunciar a hacer del entendimiento una combinación de ideas complejas, elaboradas a partir de ideas simples por un poder misterioso e inexplicable. Por otra parte, habiéndose contentado hasta el momento con describir un cierto número de facultades elementales directamente salidas de la sensación, no puede renunciar ahora a hacer de la inteligencia un producto de ésta, conservándole el carácter de don gratuito y misterioso; ello sería renegar del ideal sistemático del que la ciencia newtoniana ha mostrado la

16 DuChesnau, François, "Condlllac critique de Locke", in: Stud. Internaz. Filos. (1974), VI, pp. 94-95. 
fuerza y la grandeza. De ahí, pues, que sea preciso corregir la obra de Locke, liberarla de las contradicciones que implica y dotarla de un rigor científico que no tiene.

Mas, ¿cómo explicar las facultades más elevadas del espíritu sin hacer intervenir un principio activo de síntesis?, ¿cómo dar cuenta de facultades tan alejadas de lo sensible, como la abstracción, el juicio o el raciocinio, sin apelar a un poder dado de reflexión? Condillac encuentra la clave del problema en la invención del lenguaje. En efecto, por el uso de ciertos signos, el hombre se hace dueño de sus ideas, puede evocarlas a voluntad, puede dirigir libremente su atención y, en definitiva, no se ve constreñido, como el animal, a la mera recepción de las impresiones presentes. El lenguaje abre, pues, para el cognoscente un horizonte nuevo y complejo, lleno de contenido y trascendencia. El poder del signo revélase extraordinario; si el animal, a falta del mismo, vese arrastrado al azar por las impresiones que los objetos sensibles producen en él, el hombre, dotado de un lenguaje característico, puede disponer a su arbitrio de sus ideas y de sus contenidos de conciencia.

Ahora bien, no todo lenguaje presenta el mismo valor; existen diferentes especies de signos y no todas ellas dan origen al desarrollo de la reflexión y de las operaciones superiores del entendimiento. Condillac distingue en varios lugares de sus obras tres tipos de signos:

En primer lugar, los signos accidentales, o los objetos que algunas particulares circunstancias han enlazado con algunas de nuestras ideas, de suerte que son apropiados para despertarlas. En segundo lugar, los signos naturales, o los gritos que la naturaleza ha establecido para los sentimientos de gozo, de temor, de dolor, etc. En tercer lugar, los signos de institución, o los que hemos escogido nosotros y que solamente tienen una relación arbitraria con nuestras ideas 17 .

Las dos primeras especies de signos no son de ninguna utilidad de cara al surgimiento de la vida mental superior, pues no revisten la característica de su dependencia respecto del sujeto. Los signos accidentales dependen exclusivamente de causas externas, extrañas al cognoscente sobre las que, por definición, carece éste de potestad. Tales signos no están, pues, a disposición del sujeto de manera que pueda éste acceder a voluntad al objeto por ellos significado. Por tanto, habrá de esperarse al azar, a que la casualidad haga presente al sujeto ta- 
les signos accidentales y así poder aprehender la realidad que ellos representan. Por idénticas razones, los signos naturales no presentan para el caso interés alguno. Puesto que no son sino la consecuencia o resultado de los sentimientos del sujeto, sólo aparecerán si aquéllos efectivamente se producen; no dependerán, pues, tampoco de nuestra voluntad; sobre ellos el sujeto carece de todo dominio. "En fin -escribe Condillac -, seriamos incapaces de recordar una cosa sino en tanto que ella esté ligada por alguin lugar, a algunas de las que están a disposición nuestra. Ahora bien, un hombre que soblo posee signos accidentales o naturales, no tiene signos que estén a sus órdenes. Sus necesidades no pueden ser causa, por consiguiente, más que del ejercicio de su imaginación" 18.

Sólo los signos de institución, establecidos arbitrariamente por el sujeto, prestan un valor real al desarrollo de la vida mental superior. Sólo ellos, en efecto, hacen posible el surgimiento de la reflexión, la formación de las operaciones cognoscitivas más elevadas y la elaboración de las ideas complejas. Esta virtualidad deriva del hecho de que es el cognoscente el artífice de los mismos; es él quien los ha instituido y, por tanto, de él dependen directamente. El signo convencional es así la fuente de la reflexión; por él el sujeto se hace dueño de sus ideas, pudiendo manejarlas a voluntad. Con el signo de institución aparece en el cognoscente un nuevo poder, antes insospechado, capaz de conferirle potestad sobre sí mismo y sobre el mundo que le rodea. Si con anterioridad a la utilización del signo convencional el sujeto hallábase sumido en la dependencia de lo externo, de lo azaroso y fortuito, ahora, en cambio, puede abrirse a nuevos mundos, más ricos y complejos. El poder de la palabra hace que el sujeto sea capaz de dirigir libremente su atención, que surja la reflexión y que se fijen las ideas más complejas y comprensivas. Pensar será así utilizar símbolos convencionales, sin los cuales la función cogitativa revélase imposible.

El poder de los signos de institución en la generación de las operaciones cognoscitivas más elevadas del espíritu se muestra ya en el ámbito mismo de las ideas. En primer lugar, por lo que respecta a aquellas que son simples, la memoria no puede tener lugar si no es por los signos que el sujeto asocia convencionalmente a algunas de sus ideas. Como es sabido, la memoria se define, según Condillac, como la facultad de traer a la conciencia, no la impresión misma pasada, sino el nombre a ella asociado; la memoria no podría tener lugar, pues, sin la intervención de signos arbitrarios o de institución. El sujeto no podría

18 Condillac, loc. cit., $\$ 39$; t. I, p. 20 a. 
traer a su conciencia determinado tipo de ideas, si no fuese por la relación que la imaginación ha establecido entre ellas y determinados signos; el poder de éstos hace que aquéllas afloren a la mente. Como escribe Condillac: «... Solamente por la trabazón que tienen estos signos con ellas (las ideas simples) es por lo que la imaginación puede evocarlas a nuestra eleccion»" ${ }^{19}$.

No obstante, el poder de los signos de institución se hace aún más sensible en lo concerniente a la formación de las ideas complejas. El factor originante de éstas no es, como pensaba Locke, una facultad de síntesis inherente al espíritu, una virtualidad combinatoria, postulada sin justificación, misteriosa e inexplicable; es, por el contrario, el signo convencional, el lenguaje arbitrario, que fija en una noción única las diversas ideas simples que la constituyen. El poder de la palabra es a este respecto insospechado; por ella somos capaces de agrupar en conjuntos ideas simples en principio inconexas; por ella el entendimiento accede a. un orden nuevo de realidades cognoscitivas, privativas del ser humano y ajenas por completo al animal. Como nos dice el propio Condillac:

El espíritu es tan limitado, que es incapaz de trazarse de nuevo numerosas ideas para hacer de ellas, al mismo tiempo, el asunto de su reflexión. No obstante, necesita con frecuencia considerar a varias en conjunto. Esto lo hace con ayuda de los signos que, reuniéndolas, se las hace considerar como si no formaran más que una sola idea 20.

Por lo que respecta a las ideas complejas arquetípicas, esto es, aquéllas que no responden a modelos existentes en la naturaleza, el empleo del signo convencional se hace absolutamente imprescindible. En efecto, no podría reflexionarse sobre conceptos y nociones de índole moral, por ejemplo, sin términos del lenguaje, que fijasen claramente y determinasen expresamente el sentido exacto de los mismos. No podríase tampoco razonar en matemáticas sin ayuda de signos, que determinasen de forma precisa la significación de las diferentes nociones numéricas ${ }^{21}$. En definitiva, como concluye Condillac: «... Para tener ideas sobre las cuales podamos reflexionar, hemos de imaginar signos que sirvan de lazos a las diferentes colecciones de ideas simples, y que nuestras nociones no son exactas sino en tanto que hemos inventado con orden los signos que las deben fijar, 22 .

19 Condllac, Essai..., I, IV, I, \$6; t. I, p. 42a.

20 Condillac, ibidem.

21 Cfr. Condillac, op. cit., I, IV, I, $\$ 8$; t. I, pp. 42b-43a.

22 Condillac, $l$ c., $\$ 9$; t. I, p. 43 a. 
Así pues, el lenguaje de institución revélase imprescindible para el desarrollo de las operaciones y formaciones más elevadas del entendimiento; a falta de él, la reflexión hállase ausente y el sujeto vese sumido en la dependencia de lo externo y de las impresiones actualmente presentes a su conciencia. A este respecto Condillac alude en el Essai al caso de un joven sordo y mudo de nacimiento que, por una casualidad afortunada, adquiere el sentido del oído y la facultad de la palabra. «... Cuando hábiles teólogos le interrogaron acerca de su estado anterior -escribe Condillac-, y sus preguntas principales versaron sobre Dios, el alma, la bondad o malicia moral de las acciones, no pareció que él hubiese llevado su pensamiento hasta esas materias" ${ }^{23}$. No asociaba tampoco ningún sentido a las prácticas religiosas que le hacían cumplir. «... Llevaba una vida puramente animal, ocupado por completo en los objetos sensibles y presentes, $y$ en las pocas ideas que recibia con los ojos. Ni siquiera sacaba de la comparación de éstas todo lo que parece podria haber sacado" 24 . A juicio de Condillac, este joven, privado del lenguaje convencional, sólo podía pensar en los objetos cuando tenía una percepción actual de ellos; su atención veíase atraída únicamente por vivas sensaciones y cesaba con éstas. Si hubiese podido disponer de signos del lenguaje de institución, no habría permanecido tan largo tiempo en un estado semejante de dependencia y limitación; prueba de ello es que, en efecto, cuando aprendió a hablar, hizo inmensos progresos y supo elevarse muy rápidamente hasta los conocimientos medios de un hombre de su edad.

Así pues, sólo por el lenguaje puede alcanzarse el desarrollo completo del espíritu humano; sólo mediante el empleo de signos arbitrarios pueden las operaciones cognoscitivas elevarse hasta el grado máximo de su desenvolvimiento natural. El lenguaje revélase, por tanto, como el eslabón perdido de la cadena, como el elemento mediador entre lo simple y lo complejo, que Locke había ignorado, incurriendo en la incoherencia de un presupuesto misterioso e inexplicable, como era la facultad de síntesis. El sistema recuperaba así el rigor perdido, así como la coherencia y la exactitud exigibles a todo pensamiento filosófico. Condillac superaba de este modo a su maestro en la tarea empirista de derivar rigurosamente todo contenido cognoscitivo, por alejado y supra-empírico que pareciera, de la fuente cognoscitiva empírica, postulada en el sistema como única e irreductible. El paso, pues, hacia el empírismo radical era así decisivo.

23 Condillac, op. cit., I, IV, II, $\$ 13 ;$ t. l, p. 44 b.

24 Condillac, ibidem. 


\section{El origen del lenguaje}

Las hipótesis de Locke sobre la formación de las ideas complejas revélase, pues, absolutamente insatisfactoria. Para nada es preciso apelar a una facultad de síntesis, misteriosa e infundada; el empleo de los signos convencionales explica enteramente el surgimiento y progresivo desarrollo de esas ideas y de las operaciones más elevadas del espíritu. Por la invención del lenguaje, se abre sin cesar a conocimientos cada vez más abstractos y sublimes, y todas las facultades cognoscitivas se desarrollan sin fisuras de manera continua y regular.

Como veremos más tarde, Locke comprendió ciertamente que las palabras sirven para fijar, unir y comunicar las ideas y, en consecuencia, para asegurar la vida social. Pero las presenta sobre todo como medios de expresión (y a veces de traición) de un pensamiento ya formado, capaz de preexistir e incluso de prescindir de ellas. Condillac, en cambio, considera al signo como causa determinante del entendimiento, a falta del cual, éste no se desarrolla en toda su extensión.

Ahora bien, aquí surge de nuevo una dificultad: si el uso de los signos de institución es para el pensamiento su causa determinante, este uso, a su vez, ¿de dónde procede?, ¿no supone en el cognoscente un poder previo de reflexión, lo mismo que la reflexión, como se ha visto, suponía un poder de representación? "Parece —escribe Condillac- que no podriamos hacer uso de los signos de institucion, si no fuésemos ya capaces de una reflexión considerable para elegirlos y para asociarles ideas: ¿cómo, pues, se me objetará quizá, no podría adquirirse el ejercicio de la reflexión sino por el uso de esos signos?„25. Y en otro lugar escribe:

Es pues el uso de los signos lo que facilita el ejercicio de la reflexión; pero esta facultad contribuye a su vez, a multiplicar los signos, $y$ por ahí puede cada día alcanzar un nuevo desarrollo. Así los signos y la reflexión son causas que se prestan auxilios mutuos, y que concurren recíprocamente a sus progresos.

$\mathrm{Si}$, considerándolos en sus débiles comienzos, no se ve claramente su influencia recíproca, no tenemos más que observarlos en el punto de perfección en que hoy están. En efecto, ¿cuánta reflexión no ha hecho falta para formar las lenguas y cuánta ayuda no suponen las lenguas a la reflexión? 26

25 Condillac, Essai..., I, II, V, $\$ 49$; t. I, p. 22 b.

26 Condillac, Art de penser, I, VI; t. I, p. 733a. 
Lenguaje y reflexión se implican, pues, mutuamente; no cabe concebir al uno sin la otra; si el lenguaje es causa determinante del pensamiento, éste, a su vez, parece hallarse presupuesto en el empleo de aquél. Como dice Roger Lefevre en su artículo "Condillac maître du langage»:

Entre la lengua y el pensamiento, no hay únicamente relación de sustentación, sino reacción circular, influencia recíproca, unión congénita, y su progreso se efectúa por un proceso cíclico 27.

Condillac se ve, pues, desde ahora obligado a precisar el origen del lenguaje. No puede contentarse con mostrar la influencia recíproca entre el signo y el pensamiento; ha de describir el proceso de formación del lenguaje y examinar si, lejos de considerarse como un don gratuito y misterioso del sujeto, puede derivarse de las facultades elementales del cognoscente, directamente salidas de la sensación.

En este intento de explicación, Condillac destaca, en primer lugar, la influencia del medio social. La vida en sociedad es considerada por él como condición indispensable para el surgimiento del lenguaje. Si el sujeto no se relacionase con otros semejantes, no sentiría la necesidad de expresar sus ideas; privado de todo contacto con ellos, no se vería impelido a comunicarse y, por tanto, a inventar un sistema de signos apto para la comunicación. De ahí que, sin el entorno social, las ideas y operaciones del cognoscente no puedan desarrollarse hasta su más alto grado; como dice Condillac: "... mientras viva sin comunicación con el resto de los hombres, no tendrá en absoluto ocasión de ligar sus ideas a signos arbitrarios» ${ }^{28}$. La influencia del medio social en la formación del lenguaje es, pues, determinante.

Ahora bien, el medio social por sí solo no basta para dar cuenta del origen del lenguaje. Puede decirse que él es condición necesaria pero no suficiente del mismo. Ciertamente, el lenguaje no puede surgir en un medio inadecuado, en un entorno en que la necesidad de expresión se halle ausente; y puesto que tal necesidad sólo es posible concebirla en sociedad, el lenguaje sólo en este medio puede originarse. Mas Condillac debe describir cuidadosamente los mecanismos psicológicos de derivación de los signos de institución. Debe encontrar la fuente generadora del lenguaje en las operaciones cognoscitivas ya descritas y,

27 Roger LefEVRE, "Condillac maître du langage", in: Revue Internationale de Philosophie (1967), XXI, p. 394.

28 Condillac, Essai..., I, IV, II, $\$ 20$; t. I, p. $46 a$. 
en definitiva, si pretende establecer la continuidad genética del espíritu, debe situar al lenguaje, como una operación más del mismo, en un momento determinado del proceso de formación espiritual, cuyo primer instante o eslabón fundamental no es sino la sensación original. En el capítulo del Essai titulado "De la operación por la cual damos signos a nuestras ideas", indica brevemente el principio de la operación por la cual se constituye el lenguaje. Allí leemos:

Esta operación resulta de la imaginación, que presenta al espíritu imágenes de las que en absoluto se contaba con el uso, y de la atención que las liga con ideas 29 .

Esta operación, que Condillac considera esencial en la investigación de la verdad $^{30}$, hunde, pues, sus raíces en dos facultades simples o elementales del entendimiento; es, en efecto, del concurso de la imaginación y de la atención de donde nace, según Condillac, la invención de los signos de institución. A la primera corresponde proporcionar a la mente la imagen que habrá de convertirse en signo; a la segunda pertenece conferir a ésta el valor de símbolo, haciéndola representativa de la idea. Nada misterioso, pues, hállase en la base de la formación del lenguaje; éste, lejos de aparecer como un don gratuito e inexplicable del cognoscente, tiene su origen en lo inferior, en lo elemental, en las facultades simples del espíritu y, por lo tanto, en definitiva, en el dato sensorial originario. Ninguna instancia supraempírica ha sido necesario invocar para dar cuenta del signo de institución, fundamento de la vida mental superior; sólo la apelación al mecanismo psicológico elemental ha bastado para explicar la operación fundamental del despliegue cognoscitivo del sujeto. A partir de ahora, la descripción de la génesis de las facultades más elevadas de lo anímico será tarea fácil y sencilla.

La doctrina de Condillac sobre el lenguaje se resume, pues, en dos puntos. Por un lado, del lenguaje derivan las ideas complejas y, en general, toda reflexión inteligente; por otro lado, empero, el lenguaje origínase a su vez en lo inferior: en la imaginación y en la atención. Para explicar el progreso de los conocimientos humanos y el desarrollo del espíritu, es inútil recurrir a una potencia misteriosa e independiente de los sentidos. Locke había concebido una facultad de síntesis, cuya función era combinar los materiales proporcionados por la experiencia. Mas Condillac, guiado por un afán de sistematismo y

29 CONDILlAC, op. cit., I, IV, I; t. I, p. $40 \mathrm{~b}$.

30 Cfr. CondILlac, ibidem. 
de rigor lógico, considera que ni los juicios inconscientes atribuidos sin fundamento al alma, ni la actividad espiritual combinatoria, existen. El origen de los conocimientos más elevados y de las operaciones complejas del entendimiento es simple; hay que buscarlo en el lenguaje, y éste, a su vez, en las facultades elementales del espíritu, esto es, en última instancia, en la sensación. El eslabón perdido, la clave de la continuidad genética, es el signo; por él, establécese una continuidad perfecta entre todas las operaciones del entendimiento; por él, también, las oscuridades de la tesis de Locke son finalmente disipadas y el desarrollo de la vida psicológica adquiere un rigor absoluto. Como dice Roger Lefevre en el artículo antes citado: con Condillac «... el divorcio tradicional de lo sensible y de lo inteligible, de la experiencia y de la razón, hállase desde abora anulado; lo que funda finalmente, sobre las ruinas de la ontologia tradicional, una metafisica seria: la metafisica del espiritu»31.

\section{La concepción lockiana del lenguaje}

Interesa ahora que aludamos brevemente a la concepción que Locke presenta del lenguaje; ello nos permitirá comprobar en qué medida la aportación de Condillac al respecto es original y en qué medida aparece como subsidiaria del planteamiento de su maestro. Locke aborda el tema del lenguaje en el libro tercero del Essay, alli expone su pensamiento de forma clara y rigurosa, conteniendo sus análisis observaciones valiosas y profundas, que su discípulo Condillac no tardará en aprovechar.

Como todos sus contemporáneos, Locke concibe el lenguaje esencialmente como un medio de expresión de ideas. El lenguaje, en efecto, es para él primariamente el instrumento posibilitador del fenómeno social, el vehículo sensible mediador entre los espíritus, en definitiva: el vínculo determinante de la comunicación humana. Como el mismo escribe:

Pero como el confort y progreso de la sociedad no se podían lograr sin la comunicación de los pensamientos, se hizo necesario que el hombre encontrara unos signos externos sensibles, por los que esas ideas invisibles, de las que están hechos sus pensamientos, pudieran darse a conocer a los demás hombres 32 .

31 Roger LeFEVRE, op. cit., p. 397.

32 J. LOCKE, An Essay Concerning Human Understanding, III, 2, § 1, p. 405. 
La función comunicativa es, pues, para Locke la esencia del lenguaje. No obstante, aparece también en el Essay una función distinta, más próxima y ligada a la concepción original de Condillac. Por ella, el lenguaje se convierte en instrumento de fijación de ideas y en elemento vinculante de las mismas, posibilitador, en definitiva, de sus múltiples asociaciones y relaciones.

Asimismo -escribe Locke-, conviene tener en cuenta, en lo que se refiere a las ideas, lo siguiente:

Primero, que, al ser los signos las ideas de los hombres, y por este motivo los instrumentos de los cuales se valen para comunicar sus concepciones, y expresar a los demás esos pensamientos e imaginaciones que se encierran en sus pechos, sucede que, por el uso constante, llegan a establecer cierta conexión entre los sonidos y las ideas que significan, de tal manera que los nombres, apenas oídos, provocan casi inmediatamente ciertas ideas, como si, en efecto, hubieran operado sobre nuestros sentidos los mismos objetos que las provocan ${ }^{33}$.

Esto equivale a decir que, por el uso de las palabras, el hombre adquiere un cierto imperio sobre sus ideas; por ellas se eleva, en efecto, sobre las necesidades presentes y alcanza el dominio de ideas cuyos objetos no se dan actualmente a la conciencia. Condillac, sin duda, bebe en esta fuente de Locke cuando afirma que el sujeto, por el uso de los signos de institución, se hace capaz de reflexión. Esta observación incidental de su maestro servirá a Condillac para desarrollar ampliamente una teoría nueva del lenguaje, más rica, compleja y llena de posibilidades.

Es preciso tener en cuenta que Locke aborda el tema del lenguaje en el libro tercero del Essay, esto es, una vez que ha estudiado en el libro segundo el problema del origen, formación y desarrollo de las ideas y operaciones del entendimiento.

Así, pues - nos dice-, debo confesar que cuando comencé este tratado sobre el entendimiento, e incluso bastante tiempo después, no tenía la menor idea de que fuese necesario hacer ninguna consideración sobre las palabras. Pero después de que hube tratado sobre el origen y composición de nuestras ideas, empecé a examinar la extensión y certeza de nuestro conocimiento, y encontré que existía una vinculación tan estrecha con las palabras que, a menos que se observara detenidamente su fuerza y manera de signifi- 
car, muy poco podría decirse con claridad y certeza sobre el conocimiento, el cual, dado que versa sobre la verdad, tenía una relación constante con las proposiciones ${ }^{34}$.

Locke pensaba, por tanto, que el desarrollo de las ideas y de las facultades del entendimiento se alcanza con independencia de la intervención del lenguaje. Una vez formado el pensamiento, el cognoscente puede buscar signos convencionales, aptos para expresar los contenidos que lo integran; mas la reflexión inteligente y el entendimiento todo se constituyen con anterioridad a la elaboración del sistema de signos arbitrarios. La idea precede al signo; es el contenido básico y fundamental que el lenguaje se limita a expresar. Estudiando, pues, el origen y formación de las ideas con anterioridad a la aparición del signo verbal, Locke había concebido primariamente el lenguaje como un medio de comunicación entre las conciencias. La palabra es esencialmente el medio transmisor de la idea, el elemento primario de la relación entre cognoscentes.

Por otra parte, Locke habíase ocupado de precisar el valor exacto del signo; había sefialado la importancia de considerar los inconvenientes que el lenguaje podía presentar como medio no rigurosamente fiel de expresión del pensamiento. Como él mismo escribe: las palabras "... por lo menos, se interponen tanto entre nuestro entendimiento y la verdad que quisieran contemplar y aprehender que, como ocurre con el medio que atraviesan los objetos visibles, la oscuridad y el desorden interponen a menudo una luz ante nuestros ojos, oscureciendo así nuestro entendimiento» 35 . Así, Locke habla indicado las deficiencias del lenguaje, al tiempo que había apuntado los abusos naturales del empleo inapropiado de las palabras. Y en todo ello, el lenguaje había sido descrito por él como medio de expresión de ideas; el análisis que había hecho de las palabras sólo tenía como objetivo completar el estudio del origen y formación del entendimiento. Será Condillac quien dé un giro radical esta concepción del lenguaje.

\section{La aportación de Condillac}

La tesis de Condillac sobre el lenguaje es muy diferente. El sistema de signos convencionales es concebido por él esencialmente como un medio de reflexión y no como un instrumento de comunicación. No se trata ya de exami-

34 J. LoCKE, op. cit., III, 9, $\$ 21$, p. 488.

35 J. LOCKE, ibidem. 
nar el lenguaje como conjunto de procedimientos, más o menos artificiales, destinados a transmitir ideas y experiencias a semejantes. Importa, ahora, ante todo, estudiar el mecanismo por el que se lleva a cabo el progreso de la inteligencia. Lo esencial es destacar que en el momento en que el cognoscente dispone de un sistema de signos convencionales, el desarrollo de las ideas y de las facultades del espíritu se efectúa sin dificultad alguna. Por el intermedio del lenguaje, el sujeto se hace dueño de su reflexión. Para nada es necesario desde ahora invocar un poder misterioso de combinación; el empleo de los signos basta para poner en marcha el desarrollo de la actividad espiritual superior. Condillac hace esta interesante precisión al final del Essai, comparando su obra con la de Locke: "He intentado hacer —dice- Lo que este filósofo habia olvidado; me he remontado a la primera operación del alma, y be dado, en mi opinión, no solo un análisis completo del entendimiento, sino que he descubierto tambien la absoluta necesidad de los signos y el principio de la asociación de las ideas" ${ }^{36}$. Consciente de la extraordinaria importancia del estudio del lenguaje en la explicación del origen y desarrollo de las ideas y operaciones del entendimiento, Condillac reprocha a Locke no haber dado al signo la relevancia que tiene en la formación y despliegue del pensamiento. "Este - dice- sólo trató en el tercer libro de una materia que debio ser el objeto del segundo" 37. De ahl, precisamente, los numerosos errores presentes en su obra: "Por no haberlo becho asi -prosigue-, ha tratado muy ligeramente del origen de nuestros conocimientos, y esta es la parte más superficialmente desarrollada por él. Supone, por ejemplo, que enseguida que el alma recibe ideas por los sentidos, puede, a voluntad, repetirlas, componerlas, unirlas mutuamente con infinita variedad, y formar con las mismas toda suerte de nociones complejas» 38 . El mérito de Condillac es, pues, haber percibido en el uso de los signos, no una función secundaria del espíritu, sino la causa determinante de las operaciones más elevadas y complejas del entendimiento.

En definitiva, Condillac es el primero que ha captado toda la importancia del problema que plantea la existencia del lenguaje. Hasta él, habíase considerado tan sólo un aspecto del mismo; habíase, en efecto, señalado que en la base de todo sistema de signos convencionales debía situarse un pensamiento reflexivo; no cabe hacer uso del lenguaje de institución sin una capacidad de pensamiento determinado. De ahí, el animal, que carece del necesario poder de

36 Condillac, Essai..., II, II, III, $\$ 39 ;$ t. I, p. $114 \mathrm{~b}$.

37 Condillac, op. cit., Introduction; t. I, p. 5 a.

38 Condillac, ibidem. 
reflexión, vese limitado a la mera facultad de expresar sus vivencias instintivas: sus sentimientos y sus emociones. El uso de la palabra no se concibe, pues, más que para un espíritu que piensa. Ahora bien, siendo esto enteramente cierto, nada prueba empero que con ello quede dicho todo. Condillac subraya el otro aspecto del problema, destacando que, para asegurar el desdoblamiento interior por el que el pensamiento se opone a sí mismo, el uso de las palabras se hace necesario. Estas proporcionan al cognoscente el medio indispensable para fijar las ideas que, de esta forma, pueden asociarse y relacionarse a voluntad. Así pues, en definitiva, si el lenguaje precisa de la reflexión para constituirse, ésta, a su vez,presenta en su base la necesaria utilización del signo arbitrario. Uno y otra implícanse mutuamente; ambos hállanse solidariamente relacionados como aspectos diversos de un único y mismo proceso. De esta solidaridad nunca antes se había hablado; a Condillac corresponde el mérito de haberla destacado por vez primera ${ }^{39}$.

No obstante, Condillac no extrae de su tesis todo el fruto que cabía esperar. Más bien se limita a destacar el reverso de la teoría tradicional del lenguaje; se contenta con precisar que la fuente de la reflexión y del pensamiento hállase en el lenguaje; éste es, a su juicio, la raíz fundamental del desarrollo espiritual superior. Sentado esto, su preocupación inmediata será derivar de las facultades elementales del cognoscente $y$, en definitiva, de la sensación, la invención del sistema de signos arbitrarios; de este modo, su proyecto filosófico más deseado, la derivación del entero edificio cognoscitivo de ideas y facultades, hállase finalmente realizado. Una continuidad perfecta establécese así por el lenguaje en el espíritu; el eslabón imprescindible para la derivación completa del entendimiento se ha hallado en el signo de institución, punto intermedio entre lo elemental y simple del entendimiento y lo complejo y abstracto de éste ${ }^{40}$.

Así, pues, por la fuerza intrínseca del signo de institución, el cognoscente adquiere un poder nuevo sobre sus ideas, se hace capaz de dirigir libremente su atención y, en definitiva, accede a la reflexión.

39 «Es, pues, el uso de los signos lo que facilita el ejercicio de la reflexión; pero esta facultad contribuye, a su vez, a multiplicar los signos, y por ahí puede cada día alcanzar un nuevo desarrollo. Así, los signos y la reflexión son causas que se prestan auxilios mutuos, y que contribuyen recíprocamente a sus progresos." (CondillaC, Cours d'Etudes, Art de penser, I, VI; t. I, p. 733a).

40 Para un estudio más exhaustivo de la concepción lockiana del lenguaje en su relación con la aportación original de Condillac, cfr. F. DuchESNAU, «Sémiotique et Abstraction: de Locke à Condillac», in: Philosophiques (1976), III, 147-166. 
Mientras no dirige uno mismo su atención —escribe Condillac-, hemos visto que el alma hállase sometida a todo lo que la rodea, y si algo posee, es por una ajena virtud. Mas, si dueña de su atención, se la guía según sus deseos, el alma dispone entonces de ella misma y obtiene ideas que a ella sola debe, enriqueciéndose con su hacienda propia ${ }^{41}$.

Haciéndose capaz el espíritu de aplicar su atención a los diferentes objetos que quiere examinar, surge la reflexión inteligente. Esta capacidad no depende para Condillac de ningún poder misterioso de síntesis; deriva tan sólo del uso del signo convencional y, en definitiva, del dato sensorial originario. Establecido con precisión el origen de la reflexión y también el del lenguaje, Condillac no se detiene ahí; considera estos resultados como punto de partida para un despliegue posterior del pensamiento. La explicación y derivación de las funciones más complejas y elevadas de lo anímico será, precisamente la última tarea que Condillac acometerá en el proceso de formación y constitución del entero edificio del conocimiento humano ${ }^{42}$.

En efecto, la aparición del lenguaje en el sistema va a posibilitar el surgimiento de las funciones cognoscitivas más elevadas del espíritu. El signo arbitrario ${ }^{43}$ se convertirá, en efecto, en pieza clave del desenvolvimiento cognoscitivo superior. La génesis de estas funciones será tarea fácil de explicar 44: el lenguaje, producto de las facultades elementales, origina la reflexión; a partir de aquí, el resto de operaciones cognoscitivas derívase de forma clara y natural.

41 Condillac, Essai..., I, II, V, $\$ 51$; t. I, p. 22 b.

42 Para un análisis más completo de la concepción condillaciana del lenguaje, cfr. aparte los artículos ya citados, M. ANGENOT, "Condillac et le cours de lingüistique générale», in: Dialectica (1971), XXV, pp. 119-130.

43 La importancia que el lenguaje convencional presenta en el sistema filosófico de Condillac, puede constatarse en: B. HeNSCHEL, "L'Arbitraire du signe chez. Condillac», in: Beitr. Roman. (1970), XVI, 1, pp. 101-104.

44 Para un conocimiento exhaustivo del proceso de formación de las operaciones superiores del entendimiento, cfr., por ejemplo, Ángel J. CAPPELLETTI, "La génesis del conocimiento, de la afectividad y de la acción en la filosofía de Condillacm, in: Revista venezolana de filosofia (1975), 2, pp. 37-73. 